\title{
Discover the effect of stand structure modification on soil microbial and nitrogen loss in a water source area
}

\author{
Rongjia Wang ${ }^{1}$, Jianfeng Zhang ${ }^{1}$, Chunju Cai ${ }^{2}$, and Gang Lei ${ }^{2}$ \\ ${ }^{1}$ Research Institute of Subtropical Forestry Chinese Academy of Forestry \\ ${ }^{2}$ International Center for Bamboo and Rattan
}

February 22, 2022

\begin{abstract}
Water pollution is an increasingly prominent global problem. Soil nitrogen $(\mathrm{N})$ loss in water source areas is the main cause to result in eutrophication. But how can we control soil $\mathrm{N}$ loss effectively? To address this, we took initiatively a moso bamboo stand in the catchment area of Fushi Reservoir in Anji County — an important water source in the Taihu Lake Basin in China-as a test plot. Through field observations and analysis, it was found that by interplanting broadleaf trees in the bamboo plantation and thus modifying the stand structure, it could inhibit bacterial nitrification and consequently decreasing nitrate- $\mathrm{N}$ (the main form of soil $\mathrm{N}$ loss), accordingly alleviating $\mathrm{N}$ loss. The results indicate that through optimization of stand structure, the soil microbial community can be influenced, soil physical and chemical properties can be changed, and $\mathrm{N}$ loss can be reduced. This means that the code to halt $\mathrm{N}$ loss through modifying stand structure is revealed. No doubt, building a well-structured water source conservation forest is an effective and practicable measure to control $\mathrm{N}$ loss. Thus, it is expected that this novel research will help in controlling non-point source pollution and ensuring drinking water safety worldwide.
\end{abstract}

\section{Hosted file}

manuscript-fin.doc available at https://authorea.com/users/461849/articles/557440-discoverthe-effect-of-stand-structure-modification-on-soil-microbial-and-nitrogen-loss-in-awater-source-area

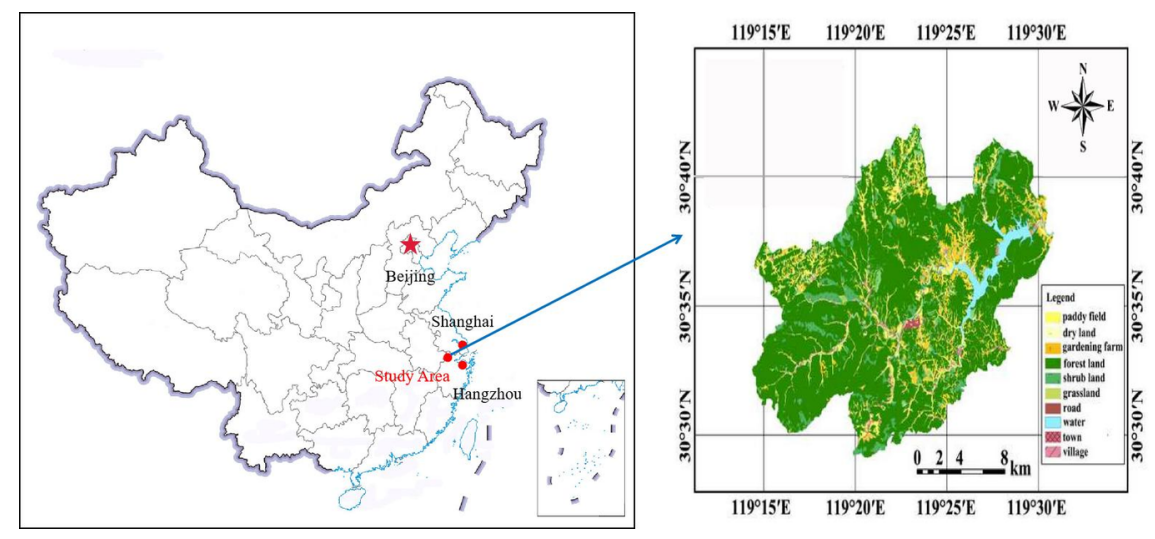



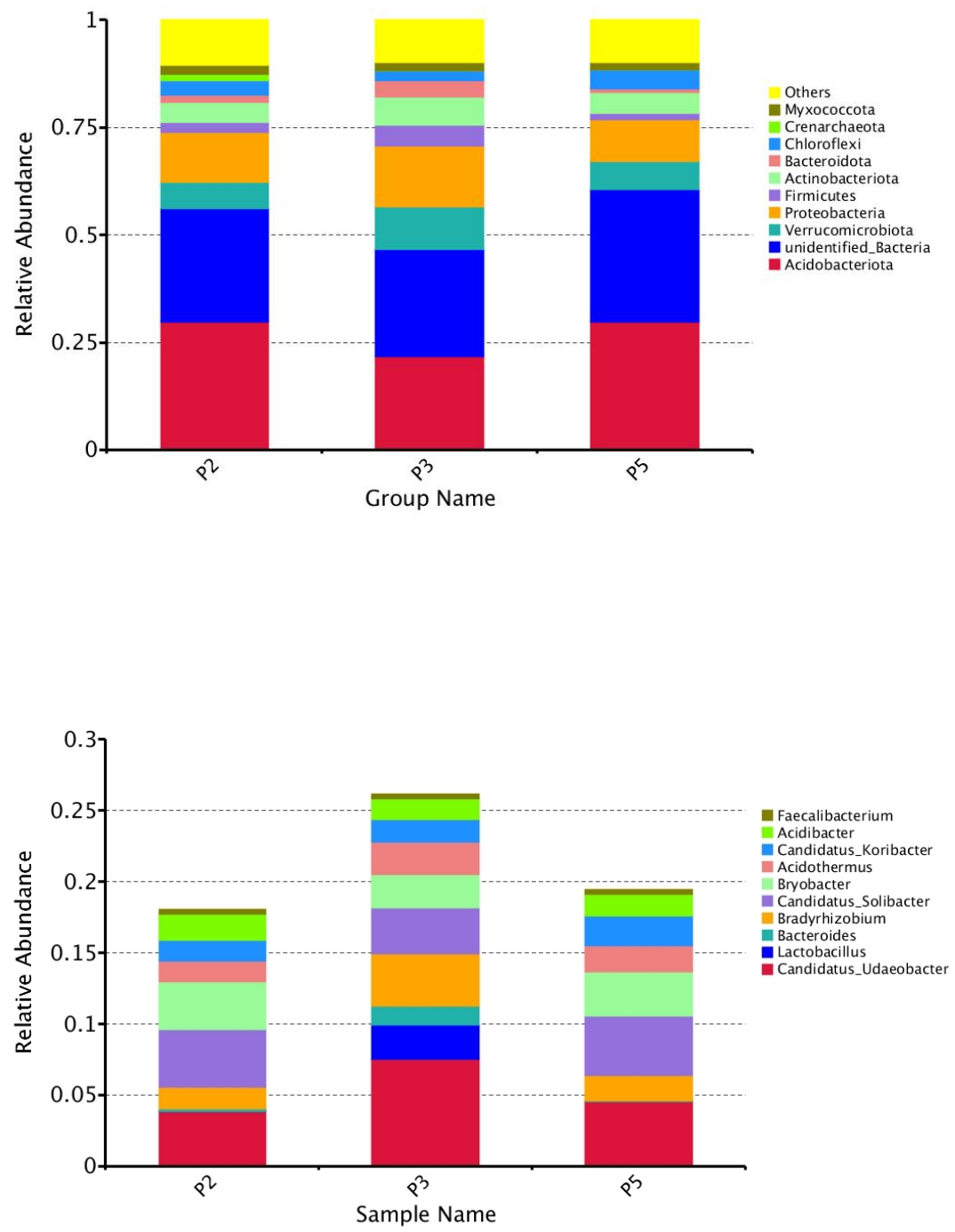

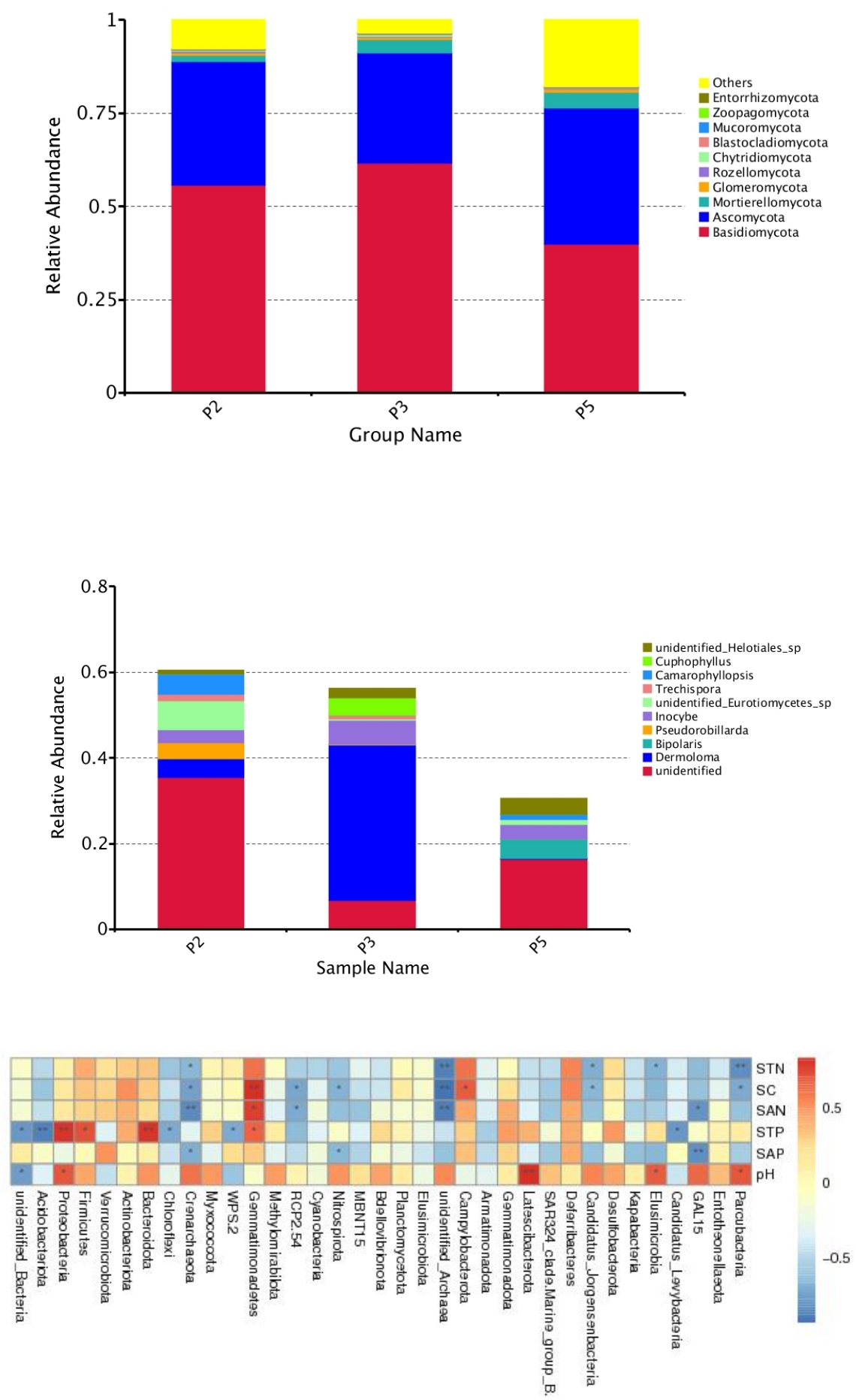

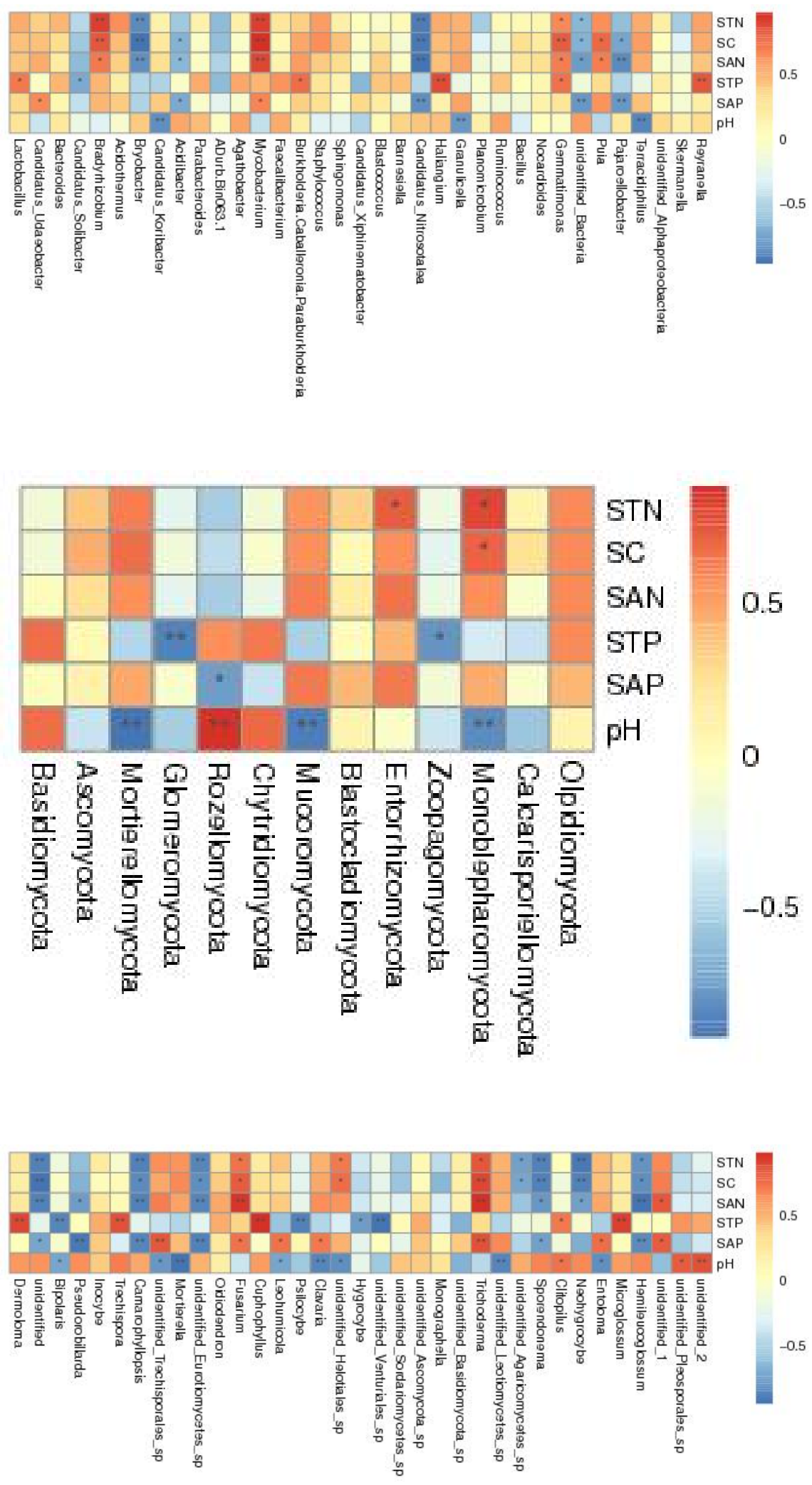
RDA Plot
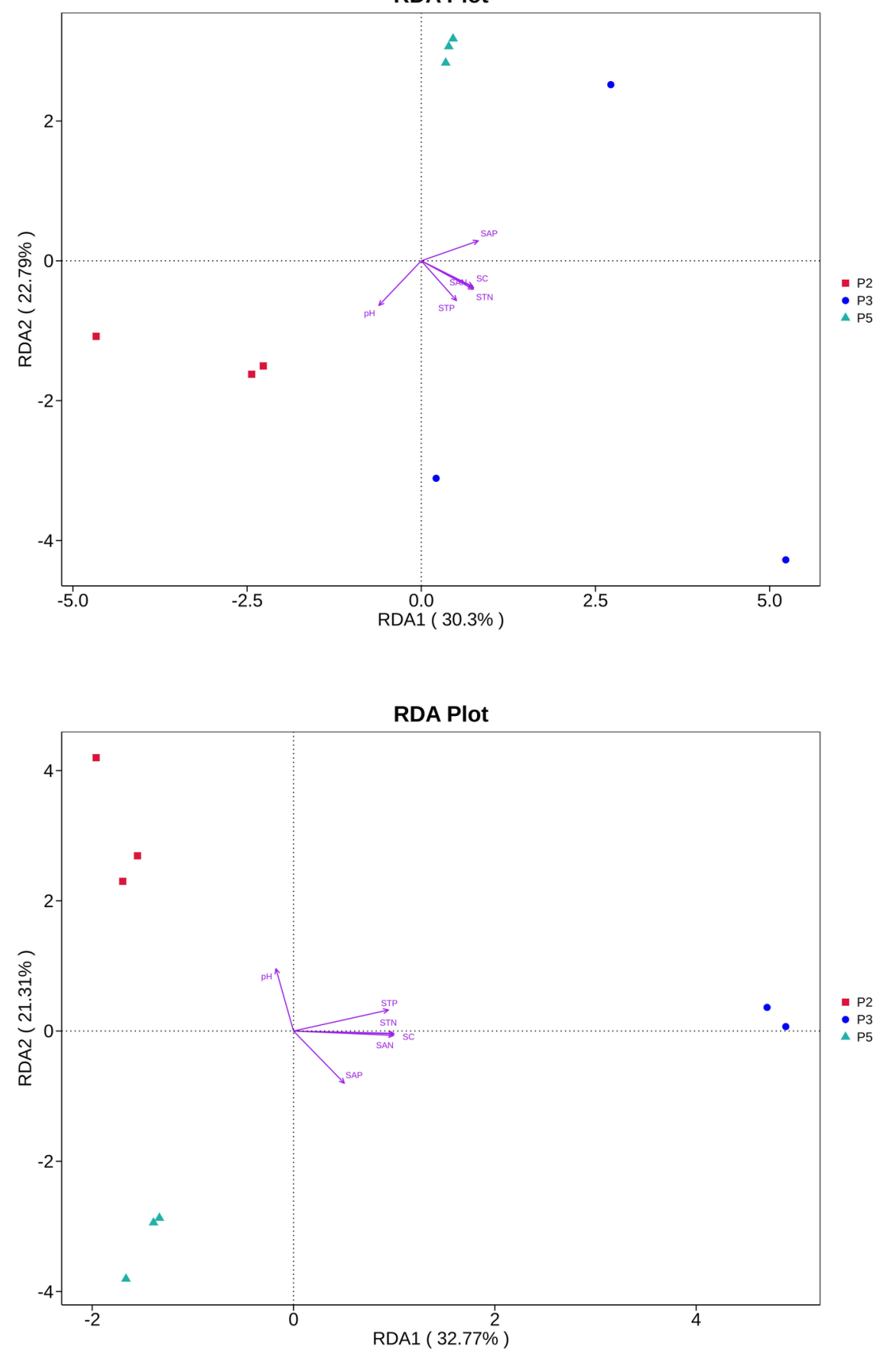


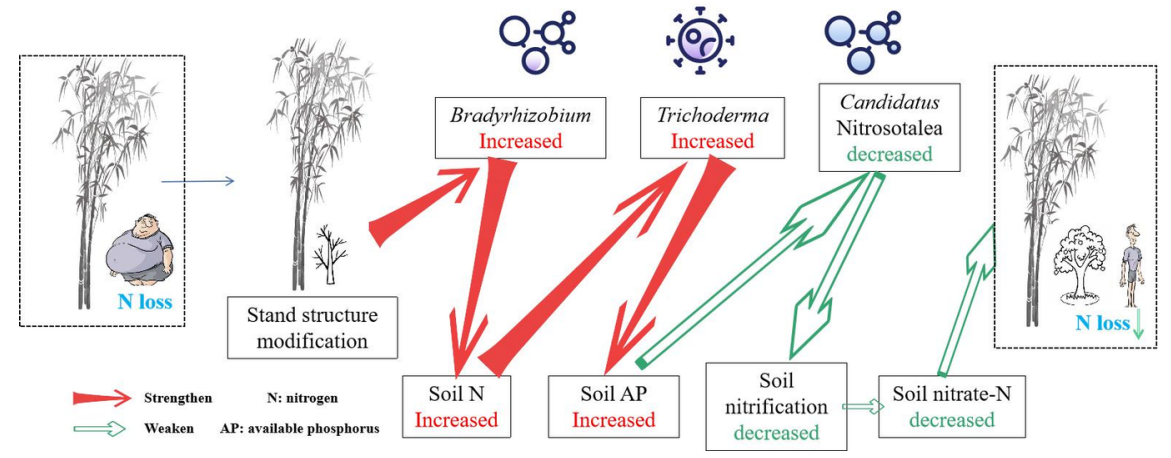

